\title{
MAKING A CASE FOR COMMUNITY SCREENING SERVICES: FINDINGS FROM A MEDICAL OUTREACH IN IBADAN, NIGERIA
}

\author{
A.M. Adebayo, O.K. Ige, O.S. Ilesanmi, T.B. Ogunniyan, and T. Ojo \\ Department of Community Medicine, University College Hospital, Ibadan.
}

Correspondence:

Dr O.K Ige

Department of Community Medicine,

University College Hospital,

Ibadan.

E-mail: drsimbo@yahoo.co.uk

\begin{abstract}
Background: Currently, population based medical check up is yet to be explored as a veritable tool for assessing the burden of non-communicable diseases in Nigeria.

Objectives: This study aimed to assess the prevalence of selected lifestyle related diseases during a free medical rally in an urban community.

Methods: General medical examinations of all participants at a free medical rally in a middle class community in Ibadan, Oyo State was conducted. Body Mass Index (BMI), blood pressure and random blood sugar measurements were done using standardised instruments. BMI classification for children was done using the CDC guidelines for males and females aged 2-20 years.

Results: Of the 302 participants examined, $33.1 \%$ were males and $32.1 \%$ were less than 18 years. Of those aged 2 to 20 years, $22.9 \%$ were underweight, while $5.2 \%$ were overweight/ obese. In adults $3.6 \%$ were underweight and $43.2 \%$ were overweight/ obese. Adults were significantly more likely to be overweight/obese $(\mathbf{P}<0.001)$. Prevalence of high blood pressure was $29.3 \%$ and $9.4 \%$ of adults had elevated random blood glucose levels. A higher proportion of obese people $(P=0.259)$, males $(P=0.327)$ and those older than 40 years $(P<0.001)$ had elevated blood pressure. A weak correlation (spearman rho $=0.3$ ) was found between blood pressure and BMI $(P<0.001)$ and also between $B M I$ and blood sugar level (spearman rho=0.2) $\mathrm{P}=0.05$.

Conclusion: There is a need for greater emphasis on community based screening programmes to aid early diagnosis and treatment of non communicable diseases in the country.
\end{abstract}

\section{INTRODUCTION}

Non-communicable diseases (NCD) are a major health burden in the industrialized countries, and are increasing rapidly in the developing countries owing to demographic transitions and changing lifestyles. ${ }^{1}$ Although these lifestyle diseases have become important threats to the health of adults in sub-Saharan Africa, efforts to detect these diseases are haphazard and prevention targets are largely inexistent. ${ }^{2}$

Most people tend to take good health for granted. It is a known fact that almost every major ailment first manifests itself as minor symptoms, which are often not noticed and hence, neglected. As such, proper preventive health check- ups are necessary for early detection and diagnoses of these health conditions. ${ }^{3}$ Carefully planned screening programmes are an important component of the strategy to help solve this problem. A major role of community-based projects is to demonstrate and stimulate a national NCD prevention policy. However one of the first, essential elements for a successful community intervention programme is a good understanding of the prevalent health problems. ${ }^{2}$

There have been arguments for and against most community based screening programmes especially about their effectiveness in detecting disease. ${ }^{4}$ However generally the consensus is that usually by the time most NCD are clinically obvious, all therapeutic endeavours and changes in habits will, at best, produce only slight improvement in the prognosis. ${ }^{3}$ It is therefore imperative that our efforts should be directed increasingly towards the prevention rather than the cure of the NCD processes. This can be done only by 
increasing public awareness of the multiple risk factors involved and, in addition, screening communities in an attempt to identify individuals who are particularly at risk. This study therefore aimed to assess the prevalence of selected lifestyle related diseases in an urban community in Ibadan

\section{MATERIALS AND METHODS}

This was a cross sectional survey conducted at Mokola, a lower class urban community in Ibadan North local government area, Oyo State. Ibadan is the capital of Oyo State, south west Nigeria. The findings obtained from the general medical examinations of all the 302 participants at a free medical rally were documented. An initial awareness campaign was conducted to sensitise the community about the medical rally. Participants included adults and children who were serially recruited as they came to the medical rally following the local publicity.

Weight, height, blood pressure and random blood sugar measurements were carried out using standardised instruments. A stadiometer was used to measure height with the respondent standing upright without shoes and against the wall, feet together and gazing forward. Height was measured to the nearest $0.5 \mathrm{~cm}$. Weight was measured with a manual Seca 761 scale (Vogel \& Halke, Germany) which was calibrated to zero each time weight was measured. Blood pressure for adults was measured in a sitting position using an Accoson sphygmomanometer and random blood sugar levels with Accucheck glucometer.

Hypertension was defined according to the JNC 7 criteria $^{5}$ as average blood pressure of $\geq 140 / 90 \mathrm{~mm}$ $\mathrm{Hg}$ after two readings. Body mass index (BMI) was calculated as weight $(\mathrm{kg}) /$ height $\left(\mathrm{m}^{2}\right)$. For adults BMI was categorised thus: underweight as $\mathrm{BMI}<18$, normal weight as BMI 18-24, overweight as BMI 25-29 and obesity as $\mathrm{BMI} \geq 30$. BMI classification for children was done using the CDC guidelines for males and females aged 2-18 years. Underweight as $<5$ th percentile, normal weight 5 th percentile to less than the 85 th percentile, overweight as 85 th to less than the 95th percentile and obese as equal to or greater than the 95th percentile. ${ }^{6}$ WHO diagnostic criteria (1999) was used as the cut-off for diabetes i.e. random plasma glucose > $11.1 \mathrm{mmol} / \mathrm{L}(200 \mathrm{mg} / \mathrm{dL})$. Data were analyzed using SPSS version 15. Associations were explored with the Chi-square test at $5 \%$ level of significance.

\section{RESULTS}

A total of 302 participants were examined.

Table 1 shows the socio demographic characteristics of patients, females were the majority 202(66.9\%) while about a third $96(31.7 \%)$ were children less than 18 years of age. The mean age of children was $8.2 \pm$ 4.7 years while the mean age for adults was $46.7 \pm$ 15.2 .

\begin{tabular}{lr}
\hline Variable & N (\%) \\
\hline Sex & $100(33.1)$ \\
M ale & $202(66.9)$ \\
Female & \\
Age groups & $97(32.1)$ \\
Children & $71(23.5)$ \\
Adults $<40$ years & $134(44.4)$ \\
Adults $=40$ years
\end{tabular}

Table 1: Socio-d emographic characteristics of responden ts

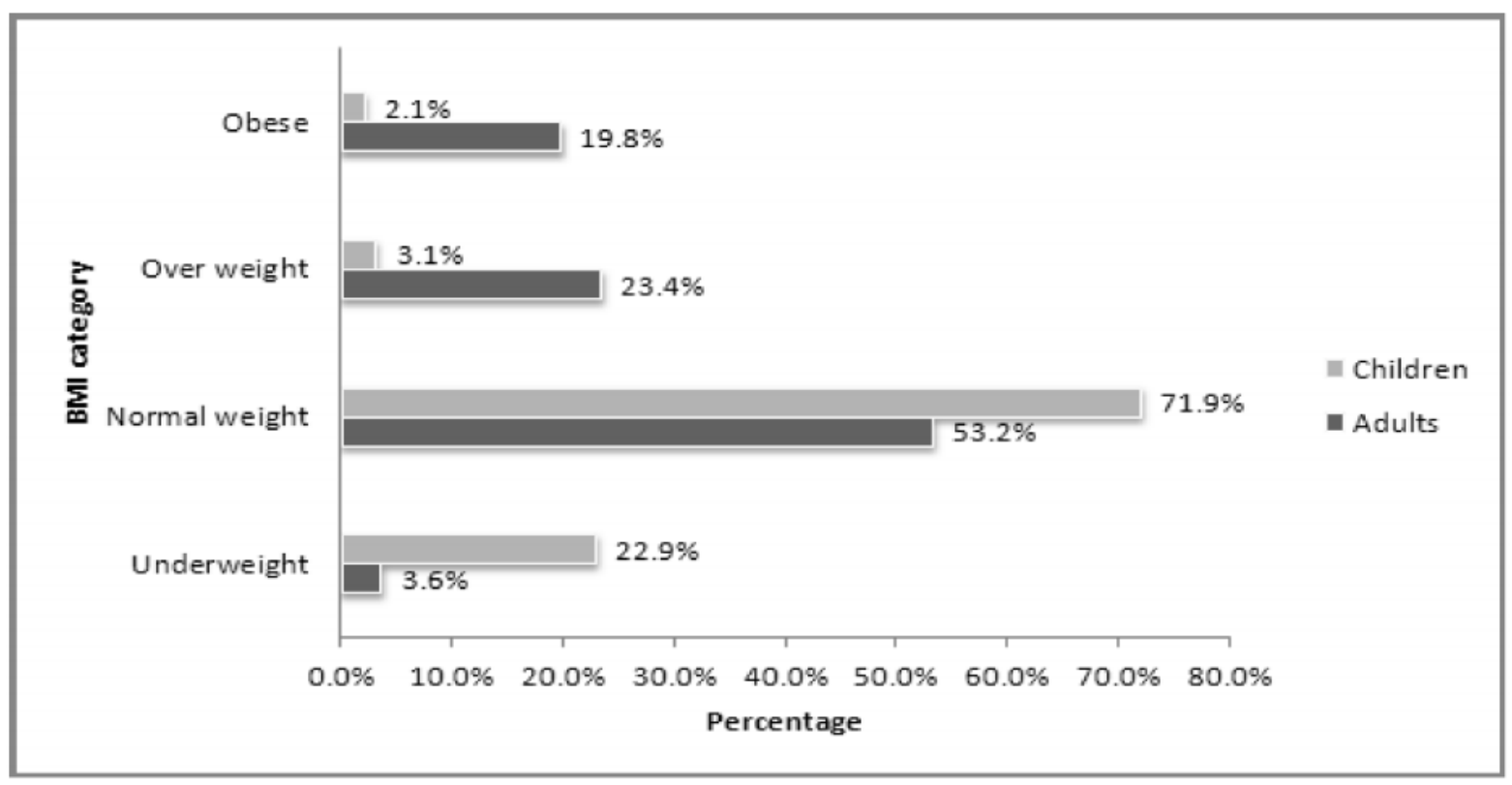

Figure 1: Body Mass Index categories of all respondents 


\begin{tabular}{|c|c|c|c|c|}
\hline \multirow[t]{2}{*}{ Variables } & \multicolumn{2}{|c|}{ Hypertension } & \multirow[t]{2}{*}{$\chi^{2}$} & \multirow[t]{2}{*}{ p value } \\
\hline & $\begin{array}{r}\text { Present } \\
\quad \text { N }(\%)\end{array}$ & $\begin{array}{r}\text { Absent } \\
N(\%)\end{array}$ & & \\
\hline \multicolumn{5}{|l|}{ Sex } \\
\hline Male & $18(34.6)$ & $34(65.4)$ & 0.962 & 0.327 \\
\hline Fem ale & $42(27.5)$ & $111(72.5)$ & & \\
\hline \multicolumn{5}{|l|}{$\mathrm{Ag} \mathrm{e}$} \\
\hline Less than 40 & $9(12.7)$ & $62(87.3)$ & 14.445 & 0.000 \\
\hline 40 and above & $51(38.1)$ & $83(61.9)$ & & \\
\hline
\end{tabular}

Table 2: Age and sex specific prevalence of hypertension am ong adults

Findings on physical examination of participants The prevalence of hypertension was $29 \%$ while the prevalence of diabetes was $3 \%$. The mean systolic blood pressure was $120.5 \pm 19.4 \mathrm{mmHg}$, and the mean diastolic blood pressure was $74.8 \pm 11.5 \mathrm{mmHg}$. Blood sugar levels ranged between $72 \mathrm{mg} / \mathrm{dl}$ and $502 \mathrm{mg} / \mathrm{dl}$ with a median value of $110 \mathrm{mg} / \mathrm{dl}$.

The classifications of the body mass index of the respondents are as shown in Figure 1. More adults were overweight and obese when compared to $(\mathrm{p}>0.05)$. However a significantly higher proportion of those aged 40 and above had hypertension compared to those less than 40 years $(38.1 \%$ versus $12.7 \%)(\mathrm{p}<0.05)$.

Age and sex specific prevalence of overweight and obesity among adults

Table 3 The prevalence of overweight did not vary significantly by the sex of the respondents $(p>0.05)$. However those 40years and older had a higher prevalence of overweight/obesity $(\mathrm{P}<0.05)$

\begin{tabular}{lcccc}
\hline Variables & \multicolumn{2}{c}{ Overweight/obesity } & $\chi^{2}$ & p value \\
\cline { 2 - 4 } & $\begin{array}{c}\text { Present } \\
\text { N }(\%)\end{array}$ & $\begin{array}{r}\text { Absent } \\
\text { N }(\%)\end{array}$ & & \\
\hline Male & $6(27.3)$ & $16(72.7)$ & 2.194 & 0.139 \\
Female & $38(44.7)$ & $47(55.3)$ & & \\
Age & & & & \\
Less than 40 & $12(27.3)$ & $32(72.7)$ & 4.063 & 0.044 \\
40 and above & $19(48.7)$ & $20(51.3)$ & & \\
\hline
\end{tabular}

Table 3: Age and sex specific prevalence of overw eight and obesity am ong adults

children however higher proportions of the children were underweight. The mean BMI for children was

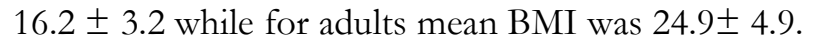

\section{Age and sex specific prevalence of hypertension among adults}

As shown in Table 2, prevalence of hypertension among adults did not vary significantly by sex although a higher proportion of men $(34.6 \%)$ had elevated blood pressure when compared to women $(27.5 \%)$

\section{Age and sex specific prevalence of diabetes} among adults

Neither sex nor age of the respondent was significantly associated with the prevalence of diabetes (P.0.05) as shown in Table 4

\section{Correlations}

Body mass index was found to be correlated, albeit marginally with blood sugar Spearman's rho= $0.2(\mathrm{P}<0.05)$, and also with blood pressure spearman's rho $=0.25(\mathrm{P}=000)$ 


\begin{tabular}{lccc}
\hline Variables & \multicolumn{2}{c}{ Diabetes } & P value \\
\hline & $\begin{array}{c}\text { Pres ent } \\
\text { N (\%) }\end{array}$ & $\begin{array}{c}\text { Absent } \\
\text { N (\%) }\end{array}$ & \\
\hline Sex & & & \\
Male & $1(3.1)$ & $31(96.9)$ & Fishers 1.0000 \\
Female & $2(2.9)$ & $67(97.1)$ & \\
Age & & & \\
Less than 40 & $0(0)$ & $26(100.0)$ & Fishers 0.567 \\
40 and above & $3(4.0)$ & $72(96.0)$ &
\end{tabular}

Table 4: Age and sex specific prevalence of diabetes among adults

\section{DISCUSSION}

This study assessed selected lifestyle related diseases in an urban community during a health fair. While some reports have demonstrated low yield during outreach programs or health fairs in community settings ${ }^{4}$ this report has shown a relatively good yield in consonance with other reports of medical outreaches ${ }^{7}$.

About 3 in 10 of respondents had hypertension similar to the $27.1 \%$ reported in a study in Ilorin ${ }^{8}$ and $29 \%$ reported in Ghana ${ }^{9-10}$. The prevalence of hypertension increased with age and BMI this is in agreement with other studies reporting that age was correlated with blood pressure and BMI. ${ }^{11}$

The proportion of children overweight or obese were strikingly different from that reported for developed countries where prevalences of more than $20 \%$ have been reported ${ }^{12-13}$ Findings are however similar to those from other studies in urban areas of Nigeria. For instance, a study in Lagos, Nigeria reported a rate of $3.7 \%$ for overweight and obesity in adolescents ${ }^{14}$. In this urban community underweight was more of a problem in children than overweight or obesity. Although there is a paucity of data on obesity in Nigerian children some studies have revealed heterogeneity in the nutritional problem by reporting a mixture of obesity and underweight. A study among Nigerian preschool children found a prevalence of overweight and obesity as $13.7 \%$ and $5.2 \%$ respectively while the prevalence of underweight was $8.5 \% .{ }^{15}$ Although childhood obesity is an evolving problem in Nigeria however obesity does not seem to be a major problem yet among children in this community.

Almost $20 \%$ of the adult participants in this study were obese showing a rise when compared to previous local studies ${ }^{11}$ in which obesity prevalence was $13.2 \%{ }^{14}$.
An earlier multinational survey documented the prevalence of obesity among Nigerian adults as $8.8 \%$ in $2000^{1}$. A more recent study in Jos, Nigeria however reported a higher prevalence of $21.4 \%$ for obesity in the adult population studied. ${ }^{16}$

In spite of the small size, this study has demonstrated that undiagnosed diabetes occurred in 3\% similar to other reports ${ }^{17}$ but much lower than the prevalence of $18.9 \%$ for undiagnosed diabetes reported in another more affluent urban population in Nigeria. ${ }^{18}$ Literature from other countries show much higher rates of undiagnosed diabetes, as high as 56\% in Saudi Arabia ${ }^{19}$ $56 \%$ in Egypt ${ }^{20}$ and $40 \%$ in Bahrain. ${ }^{21}$ This prevalence was also lower than the $6.8 \%$ and $6.3 \%$ reported among adults in Nigeria and Ghana in $2000 .{ }^{10}$ Given the increasing prevalence of obesity, it is likely that these figures provide an underestimate of future diabetes prevalence. ${ }^{22}$

Early diagnosis of chronic diseases is an important step toward reducing morbidity, mortality, and health care costs. Within the health care system, diagnosis of these seemingly asymptomatic diseases rests with primary care providers. This study demonstrates that population based health screening opportunities are useful.

\section{CONCLUSIONS}

This study highlights the usefulness of community screening services. Programs targeting early identification of non communicable diseases should thus be encouraged. Public health practitioners are encouraged to take a stronger role in community based identification and treatment of non- communicable diseases in Nigeria. 


\section{LIMITATIONS}

In a study such as we have described, biases can potentially arise from using a non random sample and also from variations in the measurements. Notwithstanding these shortcomings, and in view of the external consistency of our data with those of similarstudies, these results may well be representative of the urban population of Ibadan and be reasonably used to formulate local health policy, at least for the age groups studied.

\section{REFERENCES}

1. WHO. Surveillance of non-communicable disease risk factors. 2003 [January 10,2010]; Available from: http://www.who.int/mediacentre/factsheets/ fs $273 /$ en/.

2. Nissinen A, Berrios X, Puska P. Communitybased noncommunicable disease interventions: lessons from developed countries for developing ones. Bulletin of the World Health Organization [serial on the Internet]. 2001.

3. Chobanian A, Bakris G, Black H, Cushman W, Green L, Izzo J. The seventh report of the joint national committee on prevention, detection, evaluation and treatment of high blood pressureJNC VII report. JAMA 2003;289:25602571.

4. Michael ME, Narayan VKM, Herman WH. Screening for type 2 diabetes. Diabetes Care. 2000;23(10):1563-1580.

5. Chobanian AV, et al. The Seventh Report of the Joint National Committee on Prevention, Detection, Evaluation, and Treatment of High Blood Pressure. The Journal of the American Medical Association. 2003;289(19):2560-2571.

6. National Center for Health Statistics. CDC growth charts. United States2000 [January 10, 2010]; Available from: www.cdc.gov/growthcharts. .

7. Spijkerman AMW, Adriaanse MC, Dekker JM, Nijpels G, Stehouwer CDA, Bouter LM, et al. Diabetic Patients Detected by Population-Based Stepwise Screening Already Have a Diabetic Cardiovascular Risk Profile. Diabetes Care 2002 25 (10):1784-1789

8. Oghagbon E, Okesina A, Biliaminu S. Prevalence of hypertension and associated variables in paid workers in Ilorin, Nigeria. Nigerian Journal of Clinical Practice 2008;11(4):342-346.

9. Cappuccio FP, Micah FB, Emmett L, Kerry SM, Antwi S, Martin-Peprah R, et al. Prevalence, Detection, Management, and Control of Hypertension in Ashanti, West Africa. Hypertension. 2004;43:1017-1022.
10. Abubakari AR, Bhopal RS. Systematic review on the prevalence of diabetes, overweight/obesity and physical inactivity in Ghanaians and Nigerians. Public Health. 2008 122( 2):173-182.

11. Amodu PHO, Mbah IO, Lawson L. Prevalence Of Obesity and Dyslipidaemia in Hypertensives Seen in Abuja, Nigeria. Scandinavian Journal of Clinical \& Laboratory Investigation. 2005;65(s240):14-17.

12. Sorof JM, Lai D, Turner J, Poffenbarger T, Portman RJ. Overweight, Ethnicity, and the Prevalence of Hypertension in School-Aged Children. PEDIATRICS. 2004;113(3):. 475-82.

13. Canning PM, Courage ML, Frizzell LM. Prevalence of overweight and obesity in a provincial population of Canadian preschool children. Canadian Medical Association 2004;171 (3):doi:10.1503/cmaj.1040075.

14. Ben-Bassey UP, Oduwole AO, Ogundipe OO. Prevalence of overweight and obesity in Eti-Osa LGA, Lagos, Nigeria. Obesity Reviews. 2007;8 (6):475-479.

15. Senbanjo I, Adejuyigbe E. Prevalence of overweight and obesity in Nigerian preschool children. Nutr Health. 2007;18(4):391-399.

16. Puepet F, Ohwovoriole A. Prevalence of risk factors for diabetes mellitus in a non-diabetic population in Jos, Nigeria. Niger J Med. 2008;17(1):71-74.

17. Dahiru T, Jibo A, Hassan A, Mande A. Prevalence of diabetes in a semi-urban community in Northern Nigeria. Niger J Med. 2008 17(4):414416.

18. Nwafor A, Owhoji A. Prevalence Of Diabetes Mellitus among Nigerians in Port Harcourt Correlates with Socio-Economic Status. J Appl Sci Environ Mgt 2001;5(1):75-77.

19. Al-Nuaim AR. Prevalence of glucose intolerance in urban and rural communities in SaudiArabia. Diabet Med. 1997;14:595 - 602.

20. Herman WH, Ali MA. Engelhau Diabetes mellitus in Egypt, risk factors and prevalence. Diabet med 1995;12(1126 - 1131).

21. Al-Mahroos F, Mekeigue PM. High prevalence of diabetes in Bahrainis. Associations with ethnicity and raised plasma cholesterol. Diabetes care 1998;21:936-942.

22. Wild S, Roglic G, Green A, Sicree R, King H. Global prevalence of diabetes. Diabetes Care. 2004;27,( 5):1047-1053. 